The Geneva Papers on Risk and Insurance, 15 (No. 55, April 1990), 202-210

\title{
The Fourth Pillar and the UK Insurance Industry
}

\author{
by Amin Rajan and Penny van Eupen*
}

\section{Introduction}

This paper summarises the results of a new study on the Fourth Pillar in the insurance industry in the United Kingdom. ${ }^{1}$ The study is the first of its kind because the concept of the Fourth Pillar is novel in the UK. Currently less than 1 per cent of "retired" workers continue to have paid part-time employment that supplements income from the conventional three pillars: state pension, occupational pension and personal savings. In the accepted parlance, such employment constitutes the Fourth Pillar in the sense that it will provide an additional means of financial support to retirees at a time when the first three pillars will become increasingly inadequate due to the aging population. The part-time nature of such employment is dictated by considerations of health and leisure which are positively correlated with age.

Despite its novelty, the concept of the Fourth Pillar is becoming inevitable, albeit gradually, in the face of the newly emerging labour market and demographic trends. On the demand side, the labour market will require additional 1.5 million employees over the period 1987-95 [2]. On the supply-side, there will be a contraction of some 25 per cent in the number of school-leavers, which will curtail the overall growth in labour supply to around 900,000 employees over the same period [3]. Indeed, the increase in supply will mainly come from the rising activity rate of women which, at 67 per cent in 1987, was already high by the standards of various European countries [4]. The female activity rate may rise to 70 per cent by the year 2000 but growth of this order will mark a significant deceleration from the headlong expansion evident over the past two decades.

Thus, the UK labour market will remain in a state of excess demand. But that is not all. There will be a growing qualitative imbalance in the sense that the skills content of work will grow at a rate that will far outpace the ability of education and training systems - in the private and public sectors - to respond effectively. Indeed, the impending skills crisis will be inevitable because of the inadequate investment in education and training in the crucial decade of the 1980s when new technologies and competitive pressures caused a stepincrease in the average skills content of work.

\footnotetext{
* The authors are respectively the director and research co-ordinator at the Centre for Research in Employment and Technology in Europe, based in Tunbridge Wells, England.

1 "Etudes et Dossiers", The Geneva Association, April 1990.
} 
So, in the 1990s the quantitative and qualitative imbalances will remain the main characteristics of the national labour market, It is against this background that the new study was carried out. Its object was to identify and assess:

- the potential for the creation of part-time work opportunities for those past the statutory retirement age, as envisaged by the concept of the Fourth Pillar proposed by the Geneva Association;

- the constraints that are inhibiting the realisation of this potential; and

- the actions that need to be taken in order to overcome the constraints.

The study has had a selective focus on the insurance industry partly because, as we shall see, it has a number of features that make it more amenable to the application of the Fourth Pillar and partly because the focus on a single industry can serve to bring out the reality of various psychological obstacles in the internal labour market within various companies.

\section{Research method}

Earlier in the pilot stage of the study, it became clear that the traditional approach, involving a postal survey of employers' perceptions of their human resource needs and the role of the Fourth Pillar in fulfilling them, would not be satisfactory. This was partly because of the novelty of the concept and partly because employers had not thought through their strategic responses to the impending demographic changes.

Accordingly, the research method relied on an iterative approach, involving a series of sequential interviews with senior personnel specialists in a representative sample of companies in the UK insurance industry. In the first instance, the interview sought to familiarise these specialists with the Fourth Pillar, demographic developments and future trends in labour demand in the economy as a whole. Out of this familiarisation process emerged an assessment of individual company's own labour demand and the role of part-time work for retirees in meeting it. The assessment also identified various potential constraints to the Fourth Pillar as well as certain practical solutions that had the best chance of overcoming them.

The interview process relied on an elaborate checklist of questions which sought to provide a structure to the discussions which formed the basis of individual company case studies. In all, some 20 representative organisations were involved, covering all classes of insurance business with the following breakdown: 6 composites, 2 reinsurers, 5 life offices, 2 general offices and 5 insurance brokers (including Lloyds of London).

The material emerging from the case studies form the basis of the findings. Where relevant, it has also been augmented by a literature survey of previous studies in three related areas: employment of older workers, demographic trends and reform of social security systems.

The checklist of questions used in the interviews and other aspects of the research method are described more fully in the report. The rest of this paper now goes on to cover the three main elements of the study's objectives in the next three sections respectively and then draws out the main conclusions in the final section. 


\section{Potential for the Fourth Pillar}

The longer-term pattern of the UK insurance industry's employment growth is given in Table 1 from which it is clear that the underlying trend has been upwards, with the bulk of growth occuring in full-time jobs. The increase stems from two sources: an income elasticity of demand for insurance greater than unity [5]; and successive budgetary changes favouring life and pension products.

\section{Table I UK Insurance Employment}

(thousands)

\begin{tabular}{|c|ccc|c|}
\hline & $(\mathrm{a})$ & $(\mathrm{b})$ & $(\mathrm{c})$ & $(\mathrm{d})=(\mathrm{a}+\mathrm{b})$ \\
\cline { 2 - 5 } & Male & Female & $\begin{array}{c}\text { Part-time } \\
\text { female }\end{array}$ & Total \\
\cline { 2 - 5 } 1981 & 125 & 100 & 17 & 225 \\
1983 & 131 & 97 & 17 & 228 \\
1985 & 123 & 103 & 19 & 226 \\
1987 & 132 & 120 & 17 & 252 \\
1989 & 136 & 129 & 19 & 265 \\
\hline
\end{tabular}

Source: Employment Gazette, various issues.

With the completion of the single market in 1992, the UK insurance industry is poised for continuing growth in business volume directly and employment indirectly because of its strong comparative advantage vis-à-vis European insurers, accumulated over years due to a favourable prudential regime, expanding home market and technological progressivity. As a result, the industry's employment is predicted to increase by an average of 3 per cent per annum in the medium term [6]. Thus in quantitative terms, the industry is likely to be creating new job opportunities.

On the qualitative side, too, the omens are good. The stock of human capital has been expanding and will continue to do so in this decade. Specifically, the case studies show that the occupational structure has been changing in favour of those occupations possessing one or more of seven attributes: higher educational qualifications, technology skills, long and varied work experience, prolonged company-based training, strong familiarity with changing tax and environmental legislation, sales and marketing expertise, and procedural skills.

This much became clear from the companies' assessment of the quantitative and qualitative changes in various occupations in the 1990s: quantitative, in the sense of numerical changes; and qualitative, in the sense of changes in the skills content of work performed within the listed occupations. Table 2 lists the occupations along the quantitative and qualitative continuums. In this decade, the approximate percentage distribution of jobs in the four segments in Table 2 is shown in Table 3 which also indicates the importance of each segment in terms of its amenability to the Fourth Pillar. 
Table 2 Main Occupational Changes in the Insurance Industry: 1989-99

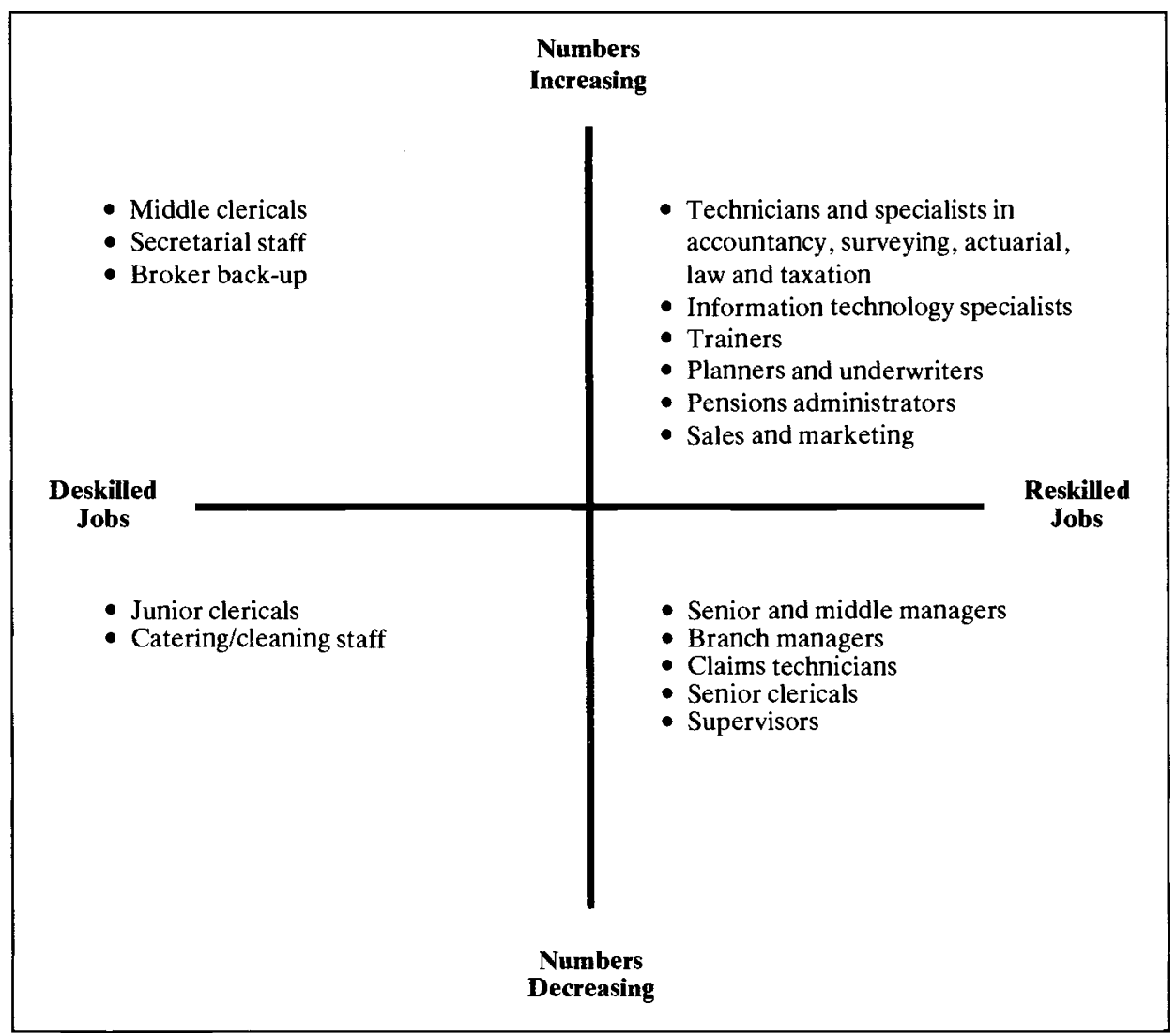

Source: Case studies

Table 3 Distribution of Employment by segments and their importance in the Fourth Pillar Context: 1988-99

\begin{tabular}{|l|c|c|}
\hline & percentage & $\begin{array}{c}\text { Ranking, indicating } \\
\text { importance in the } \\
\text { Fourth Pillar context }\end{array}$ \\
\cline { 2 - 3 } North-east segment & 25 & 1 \\
South-east segment & 15 & 2 \\
North-west segment & 40 & 3 \\
South-west segment & 20 & 4 \\
\hline
\end{tabular}

Source: Case studies 
The case studies have identified the potential for the Fourth Pillar in the first three segments in Table 3 . This is because they have two sets of attributes which specifically favour older employees.

First, their average skills content of work is increasing due to one or more of six factors: new technology, changing legislations, growing customer sophistication, shorter product cycles, product customisation and work redesign, leading to the performance of various sequential functions under one job. With the completion of the Single European Market the impact of these factors is expected to be even more pronounced because of the fresh competitive pressures in the enlarged market. As a result, companies in the UK insurance industry will be confronted by two challenges:

- how to meet their rising recruitment needs against the background of demographic changes described in Section 1 ?

- how to resource their skills needs as market forces require a continuing enhancement in the stock of human capital?

As companies prepare to face these challenges, the logic of the Fourth Pillar becomes incontrovertible. Statistics emerging from our research amply corroborate this proposition:

- 70 per cent of the companies in our sample viewed the Fourth Pillar as inevitable;

- 20 per cent were already implementing it, albeit on a modest scale, in areas such as business planning, broker support and training.

The sense of inevitability is reinforced by three developments. First, the Government has recently initiated yet another review of the national pension regulations with a view to devise a more flexible regime. Second, the application of new technology is continually permitting the decentralisation of work away from the inner-city areas such that the average travel-to-work time for many employees is contracting. The development is particularly favourable to those who work part-time because they do not like to undertake journeys that appear disproportionately long in relation to the hours worked. Finally, with a gradual decline in the size of the working week and longer holidays, most employees are having more time for leisure. Thus with leisure opportunities increasing during the working life, the traditional incentive to retire so as to enjoy greater leisure was weakening.

Yet, the fact that logic is on the side of the Fourth Pillar does not necessarily mean that it will soon take root and flourish across the insurance industry. This is because there remain various constraints which will continue to retard its applications in some companies and slow down the pace in others.

\section{Constraints}

From the case studies, it is clear that the potential for the application of the Fourth Pillar clearly exists in the UK insurance industry. It is equally clear that its realisation would be a long haul because of the persistence of three formidable constraints: one relating to the recent rationalisation programme, one to individuals' perceptions of status and one to the growing competition for part-time work.

Taking then in turn, the 1979-81 economic recession led to severe cost pressures in the industry, resulting in an enforced programme of rationalisation. Amongst others, the programme involved voluntary and involuntary redundancies especially among staff over the age of 50 . In fact, the programme has generated two legacies, both of which are inimical to 
the application of the Fourth Pillar. First, the retirement age has been reduced de facto from 65 to 62 for men and from 60 to 57 for women. Indeed, a new corporate culture has evolved that actively encourages staff to opt for earlier retirements. Second, and more importantly, many staff in the 55+ age group have in fact retired earlier with the result that the potential pool of part-time retirees has contracted. This is evidenced by the changing age structure, shown in Table 4. Translated in absolute numbers, in 1980 some 29,000 staff members would have been available for part-time work after the retirement age over a ten years span. By 1989 , that pool had shrunk to 15,000 . This is a direct result of the early retirement programmes. Yet, in the context of generating a viable Fourth Pillar, this is a major retrograde step because the main appeal of offering part-time employment to retirees lies in the opportunity they provide the insurers to capitalise on the accumulated insurance expertise internalised by such staff through education, training and work experience during their career in the insurance industry. Retirees from outside the mainstream insurance area are deemed unfit to enter the jobs in the first three critical segments listed in Table 3.

Table 4 Changing Age Structure: 1980-89

\begin{tabular}{|c|c|c|}
\hline \multirow[b]{2}{*}{ Age Group : } & \multicolumn{2}{|c|}{ Percentage of staff in } \\
\hline & 1980 & 1989 \\
\hline Under 55 years & 87 & 94 \\
\hline $55-60$ years & 10 & 5 \\
\hline $60-65$ years & 3 & 1 \\
\hline Total & 100 & 100 \\
\hline
\end{tabular}

Source : Case studies

Moving on the second constraint, it is clear that it is in fact inter-related with the first one. As in most other industries, the insurance industry's seniority system has ensured that the older a person is the higher up in the occupational ladder $s /$ he is likely to be. On this reckoning, it is highly likely that those 15,000 staff who may have been potentially available for part-time work upon reaching the statutory retirement age will have been in relatively senior positions. A majority of them will have been male because women tend to be concentrated in lower level occupations where the staff turnover rates tend to be high. Be that as it may, it is most unlikely that those becoming eligible might have opted for part-time work if this involved a loss of job status. This is because the psychological cost of part-time work may seem unduly high. On the other hand, if the part-time retirees are to retain their previous status, there could well be severe problems arising from career blockages and demotivation for those in the age group 40-55 directly and in the younger age groups indirectly. At any rate, retention of status by part-time retirees could well create major difficulties in the recruitment and retention of staff in other age groups.

The third and final constraint relates to the emergence of a competitive group. In the last decade, new technology and redesign of work have indeed created part-time opportunities, as evidenced by the third column in Table 1. But these have gone to women. Many 
insurance companies have introduced or are introducing special career break schemes for women. Under them women are able to return to work on a part-time basis, after having a family [7]. Indeed, in the economy as a whole, over 80 per cent of the increase in the labour force over the period 1987-95 is likely to be accounted for by women returners [8]. Accordingly, insurers and brokers are increasingly targeting their recruitment on them to the extent that older staff reaching retirement age are not even considered as serious alternatives. That aside, it is essential to emphasise that women returners have hitherto joined in the north-east segment in Table 2, whereas the skills shortages are likely to appear in the north-east and south-east segments. Therefore, the fact that women are returning to work in the lower and middle level occupations does not preclude the creation of part-time work opportunities in professional, technical and higher level occupations where the skill content of work will continue to rise.

So much for the constraints. They are real and formidable, being born of historical, psychological and demographical imperatives. It is equally clear that as a result of the twin challenges mentioned in Section 3, the constraints are likely to weaken, albeit slowly, to the extent that the Fourth Pillar is gaining reality in certain companies. It is now time to consider the actions that can hasten its pace.

\section{Actions}

Three sets of actions are being viewed as being essential in order to enhance the scale of part-time work for retirees : one relating to redesign of work, one relating to the national regulations on pensions and one to the emergence of role models.

Taking them in turn, it is clear that the UK insurance industry has achieved a substantial measure of work redesign in two respects $[9 ; 10]$. First, there has been a significant geographical decentralisation of work, under which many head office functions in the disparate areas of premium renewal, underwriting, claims processing and accounts have been devolved to regional offices in order to save rents on expensive inner-city sites. Second, alongside there has also been reloading of work so that an increasing proportion of staff perform multiple functions under one job. Both these developments have helped from the point of view of the Fourth Pillar : decentralisation has eased travel to work and job loading has promoted the development of multiple skills by many individual staff members. As such the foundation has been laid for new initiatives that can be directed at providing the following work arrangements and practices:

- tele- or home-working, so that travel to work for part-time retirees can be eased further;

- consultancy status, such that part-time retirees can continue to perform significant tasks without a perceived loss of status. Their work can be organised on a task force basis, taking them into different business areas, departments and locations, thereby directing their accumulated expertise at a variety of ad hoc tasks;

- recruitment from other companies in the insurance industry, in order to minimise any perceived loss of status. Such inter-company transferability of older staff within the industry provides the most practical means of overcoming the psychological resistance. At present, beyond the age of 50 hardly any inter-company moves occur;

- creation of a special corps of trainers, mainly comprising those who have passed retirement age. As well as overcoming the issue of status loss through creation of an elite army 
of "gurus", this avenue has the additional merit of internalising within the company the accumulated expertise of those with long experience in the insurance business. As the skills content of work increases, the need for more trainers will grow.

So much for new initiatives in the area of work redesign and practices. Moving on to the second set of actions, this relates to the rules concerning taxation of earnings of retirees and the retirement age itself. Since October 1989, the so-called earnings penalty has been abolished in the UK. Previously, anyone working after reaching statutory retirement age lost 50 pence of the state pension for every $£ 1$ earned over $£ 75$ per week; and $£ 1$ for every $£ 1$ earned over $£ 79$ per week. Thus there was a 100 per cent marginal tax rate effective at a modest threshold of income. Under the revised rules, pensioners can keep their pensions and any earned income. Thus an incentive for part-time work for pensioners has been created. However, it has to be mentioned that in the Fourth Pillar context this reform does not directly relieve pressure on state finances. But indirectly it can help over time as it may enable the government to let the real value of pensions to drop through only partial price indexation, thereby relieving pressures on the state finances on the one hand and promoting the emergence of the Fourth Pillar on the other. In this context, arguably the recent reform is in the right direction.

But in order to hasten the pace of the Fourth Pillar, significant steps are needed towards achieving flexibility in retirement age. The current practice under which the age is fixed is a major psychological barrier because it substantially conditions the behaviour of employers and employees. Our research identified the current state stipulations as a major stumbling block. The Government, accordingly, has a dual challenge to meet :

- how to promote the concept of the Fourth Pillar through a more flexible retirement system?

- how to relieve the fiscal burden of having an additional 25 per cent of pensioners in this decade? [11]

In this context, a major review is in progress at present. The last two reviews came to grief because the implied political cost of reform was unacceptably high in electoral terms. But unless the current system is made more flexible, the concept of the Fourth Pillar is unlikely to witness a major momentum even when the labour market and demographic pressures intensify.

The final set of actions relate to the overt creation of role models. The notion of a set retirement age is so deeply ingrained in the corporate philosophy, remuneration system and career progression that it constitutes a major psychological barrier to the rapid emergence of the Fourth Pillar. Like other barriers, it is formidable only because it is perceived to be so. As in all areas where ingrained attitudes are deep-rooted, the emergence of role models can serve to "break the ice". Not surprisingly, there was a strong consensus in our case study interviews that once certain companies visibly and significantly introduced the Fourth Pillar, other may soon emulate them. Indeed, this has been borne out by good practices in the employment of women and ethnic minorities: enlightened initiatives by some companies have been, over time, emulated by others.

\section{Concluding comments}

By way of conclusion, it is worth restating the two laws of social progress. The first one postulates that what is economically and socially desirable does not necessarily happen; 
or, at any rate, does not happen at an ideal pace because of various impediments. These are not God-given : most of them can be overcome, especially if logic is on the side of aims that we wish to promote. The laws apply to all social innovations, including the Fourth Pillar. There is little doubt that it will occur in the UK insurance industry under the combined impact of demographic changes and the rising skills content of work. The proposition is based not only on logic but it is also based on the evolving perceptions of the decision makers in the area of human resource management. But arguably the emergence of the Fourth Pillar will be a rather slow process because of the time-honoured constraints: the de facto reduction in the retirement age, the desire of part-time retirees to retain their previous work status and the emergence of a competitive group in the form of women returners.

Durable though they have been, these constraints are not immutable. They can be overcome through three sets of action: new initiatives in the area of work redesign, creation of greater flexibility in the state pension system and the promotion of role models.

The fact that these constraints have prevailed for so long does not necessarily mean that the concept of the Fourth Pillar will not become a practical reality on a notable scale. What it means is that, like other social innovations, the Fourth Pillar will have to wait its turn in the queue and manifest itself slowly as the labour market pressures intensify.

\section{REFERENCES}

1. RAJAN, A., and VAN EUPEN, P. (1990): "The Fourth Pillar and the UK Insurance Industry", Report commissioned by the Geneva Association from the Centre for Research in Employment and Technology in Europe.

2. WILSON, R.M. and R. A., (eds): Review of the Economy and Employment, 1988/89, Institute of Employment Research, University of Warwick.

3. RAJAN, A., (1990): 1992: "A Zero Sum Game-Business, Know-how and Training Challenges from an Integrated Europe", Industrial Society Press, London.

4. Employment Outlook, $(1988,1989)$, OECD, Paris.

5. DIALON, S., (1985): "The Insurance Industry-Structure, Developments and Market Prospects to 1990", Staniland Hall Associates Ltd, London.

6. RAJAN, A., (1989): "The UK Insurance Industry and 1992 - The Business and Human Resource Challenges", Commission of the European Communities, Brussels.

7. RAJAN, A. and VAN EUPEN, P., (1990): "Good Practices in the Employment of Women Returners", Institute of Manpower Studies, Brighton, England.

8. Employment Gazette (September 1988), Department of Employment, London.

9. RAJAN, A., (1985): "New Technology and Employment in Insurance, Banking and Building Societies", Gower Publishing, Aldershot, England.

10. RAJAN, A., (1987): "Services - The Second Industrial Revolution", Butterworths, Sevenoaks, England.

11. Social Trends, (1989), Central Statistical Office, London. 